\title{
A long-term subacute sclerosing panencephalitis survivor treated with intraventricular interferon- alpha for 13 years
}

\author{
Minsun Kwak, MD', Hye-Ryun Yeh, MD', Mi-Sun Yum, MD', Hyun-Jin Kim, MD', Su Jeong You, MD², Tae-Sung Ko, MD \\ ${ }^{\prime}$ Department of Pediatrics, Asan Medical Center Children's Hospital, University of Ulsan College of Medicine, Seoul, ${ }^{2}$ Department of Pediatrics, Inje University \\ Sanggye Paik Hospital, Inje University College of Medicine, Seoul, Korea
}

Subacute sclerosing panencephalitis (SSPE) is a rare, progressive, and fatal central nervous system disorder resulting from persistent measles virus infection. Long-term data are scarce, with a maximum follow-up period of 10 years. Interferon-alpha (IFN- $\alpha$ ) is a protein that exerts its antiviral activity via enhancement of cellular immune response and is reported to be an effective drug for the treatment of SSPE. However, there is currently no consensus regarding the optimal duration of IFN- $\alpha$ therapy. Here, we present a case report of a patient with SSPE treated with long-term intraventricular IFN- $\alpha$ therapy, which facilitated clinical improvement and neurological stabilization without causing serious adverse effects. To the best of our knowledge, this is one of the longest follow-up studies investigating a patient with SSPE receiving intraventricular INF- $\alpha$ treatment. Further studies are necessary to validate the benefits and safety of long-term intraventricular IFN- $\alpha$ treatment in patients with SSPE.

Key words: Subacute sclerosing panencephalitis, Measles, Intraventricular interferon-alpha, Long-term treatment

\section{Introduction}

Subacute sclerosing panencephalitis (SSPE) is a progressive and fatal inflammatory disease of the central nervous system caused by persistent, aberrant measles virus infection. After a latency period of 6-8 years, subtle and slow cognitive decline and visuospatial disorientation develop, followed by myoclonic jerks, extrapyramidal symptoms, ataxia, and seizures, with progression to a vegetative state or death within several years. ${ }^{1,2)}$ Spontaneous remission and prolonged survival beyond 4 years is rarely reported, and there is no known cure for SSPE as far as we know. ${ }^{3)}$ While several trials have studied the ability of interferon-alpha (INF- $\alpha$ ) to prolong the lives of patients with SSPE, resulting in the stabilization and improvement of neurologic disability in 30\% of patients, the optimal duration of INF- $\alpha$ therapy is unknown. ${ }^{4,5)}$ Herein, we report a case of a long-term SSPE survivor treated with intraventricular INF- $\alpha$ and a brief literature review.

\section{Case report}

A 13-year-old boy was transferred to Asan Medical Center with gradually progressing diffuse rigidity, cognitive deterioration, and generalized myoclonic seizures minimally responsive to valproic acid medication that had begun several months ago. He had steadily lost
Corresponding author: Tae-Sung Ko, MD Department of Pediatrics, Asan Medical Center Children's Hospital, University of Ulsan College of Medicine, 88, Olympic-ro 43-gil, Songpa-gu, Seoul 05505, Korea

Tel: +82-2-3010-3381

Fax: +82-2-473-3725

E-mail: tsko@amc.seoul.kr

https://orcid.org/0000-0002-8213-8964

Received: 26 June, 2018

Revised: 31 August, 2018

Accepted: 4 September, 2018

Copyright (c) 2019 by The Korean Pediatric Society

This is an open-access article distributed under the terms of the Creative Commons Attribution NonCommercial License (http://creativecommons.org/ licenses/by-nc/4.0/) which permits unrestricted noncommercial use, distribution, and reproduction in any medium, provided the original work is properly cited. 
social abilities and living skills such as feeding and dressing himself since the onset of his symptoms. He was born at term without perinatal event and developed normally with scheduled vaccination. His family history of neurological or metabolic disease was also unremarkable. Past medical history revealed that he experienced measles infection at age 2 years despite receiving a single dose of measles, mumps, and rubella (MMR) vaccine at age 12 months.

Prior to the onset of symptoms, his language expression or cognitive ability showed age-appropriate developmentwith an average intelligence of a 13-year-old boy. However, his symptoms rapidly progressed after the onset of the disease and the patient thereafter suffered from nearly continuous myoclonic jerk, uncontrolled generalized rigidity with swallowing difficulty, and bowel and bladder incontinence. Although he was alert, barely spoke out comprehensive sentences and showed confused mentality at the time of admission. Physical examination showed generalized stiffness and rigidity of both the arms and the legs. Ankle clonus and hyperactive deep tendon reflexes were observed. Laboratory testing for autoimmune, metabolic, and genetic etiologies were unrevealing, including skin biopsy and genetic testing for neuronal ceroid lipofuscinosis. His initial brain magnetic resonance imaging (MRI) was unremarkable, but electroencephalography (EEG) showed anterior dominant periodic lateralized epileptiform discharges on diffuse suppressed backgrounds (Fig. 1A). Based on his measles infection history and clinical manifestations, a cerebrospinal fluid (CSF) study including antimeasles antibodies was done. The CSF analysis showed normocytosis and normal glucose and total protein but positive CSF IgG and IgM antimeasles antibody and high CSF/ serum IgG index of 1.6. A right frontal brain biopsy demonstrated nonspecific perivascular lymphocytic inflammation and microglial activation with a notable absence of viral inclusions. Based on these laboratory findings, he was diagnosed as stage III SSPE according to Jabbour's classification. ${ }^{6}$ The patient was treated with oral inosiplex $(100 \mathrm{mg} / \mathrm{kg} /$ day $)$ in 3 divided doses and intraventricular $1 \times 10^{6}$ units of INF- $\alpha$ twice a week via an Ommaya reservoir for the initial 6 months following an escalating 5-day regimen. ${ }^{7)}$ Supportive therapy with clonazepam and trihexyphenidyl was also administered, and the generalized stiffness gradually improved during treatment and disappeared 1 month after initiating the combination therapy. The patient's immunomodulating therapy has been continued with a regimen of twice-weekly intraventricular $1 \times 10^{6}$ units of IFN- $\alpha$ for 13 years, with oral inosiplex administered as a combination therapy for 5 years.

At 3-year follow-up after commencing SSPE treatment, he successfully tapered his clonazepam and trihexyphenidyl, and no myoclonic jerk remained. He has shown some improvement in hypertonicity. He could communicate by expressing his intention with gestures. Despite this noticeable improvement in clinical symptoms during the first 3 years of treatment, his symptoms slowly degenerated thereafter. Eight years after treatment initiation, generalized periodic complexes disappeared and evolved to diffuse background suppression on EEG (Fig. 1B), and his follow-up brain MRI revealed progressive diffuse brain atrophy and periventricular T2/ fluid-attenuated inversion recovery signal changes (Fig. 2B).

At the time of this report, at the age of 25 years, he can express himself with babbles and facial expressions in a bed-ridden status and remains in stage III SSPE.

During the 13-year treatment with intraventricular IFN- $\alpha$, no serious adverse events occurred except 1 episode of bacterial meningitis that was successfully treated. Follow-up evaluation of the CSF IgM antimeasles antibody revealed prolonged persistence of the CSF IgM antimeasles antibody, followed by conversion to negativity at 10 years after treatment initiation. The CSF/serum IgG index and CSF IgG antititer have been observed to rise and fall over the 13-year period.

This study was approved by the Institutional Review Board (IRB) of Asan Medical Center (2018-0760). As a retrospective case report, written consent was waived by the IRB.
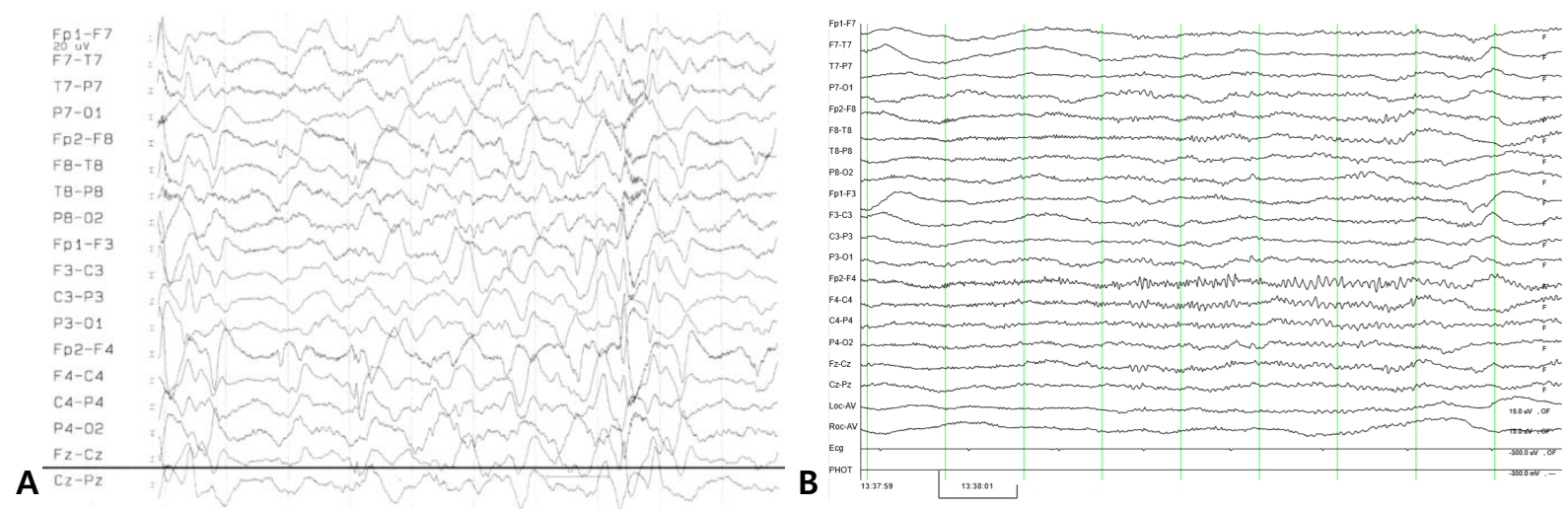

Fig. 1. (A) Initial recording showing anterior dominant periodic complex discharges. (B) Recordings from 7 years later showing the disappearance of the periodic complexes, leaving diffuse background suppression. Image displayed at 20 seconds per page with a sensitivity of $10 \mathrm{MV}$. 

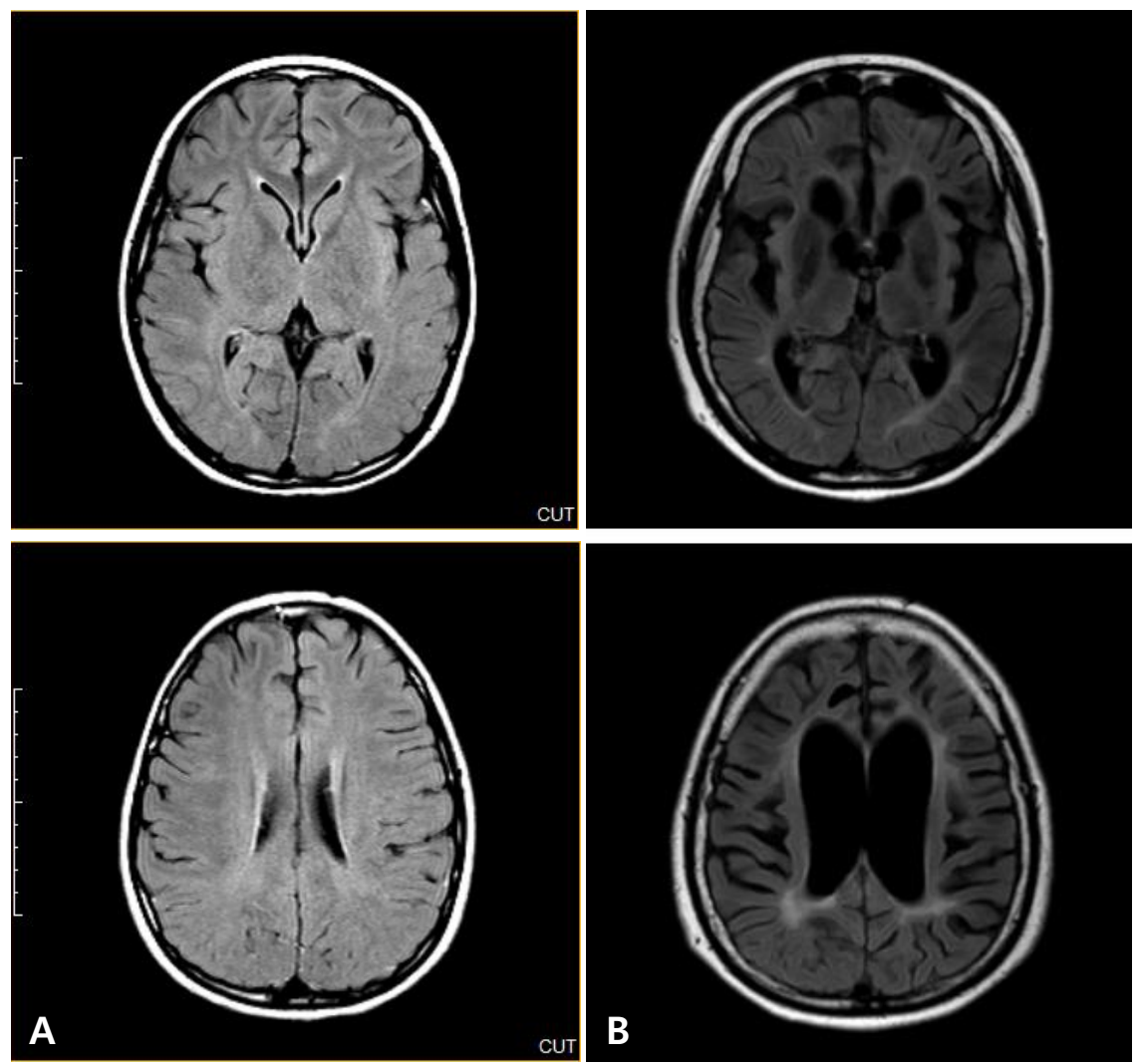

Fig. 2. (A) Initial brain magnetic resonance imaging following patient diagnosis. Axial fluidattenuated inversion recovery (FLAIR) images were unchanged. (B) Eight years following diagnosis and treatment of subacute sclerosing panencephalitis with interferon- $\alpha$, periventricular signal changes and diffuse brain atrophy were observed in these axial FLAIR images.

\section{Discussion}

Prior to implementation of the national measles elimination plan, our country experienced multiple measles epidemics in the 1990s. In addition, 5\%-7\% of individuals are not protected after a single dose of a measles-containing vaccine. ${ }^{8)}$ As measles infection during infancy is a definitive SSPE risk factor, early doses of MMR vaccine are recommended in high-risk young children. ${ }^{8)}$ A recent study reported on SSPE cases detected in California and estimated the risk of SSPE for children who contracted measles at $<5$ years of age and infants $<12$ months of age to be 1:1,367 and 1:609, respectively. ${ }^{8)}$ The authors emphasized the importance of maintaining high population immunity as well as the protection of incompletely vaccinated infants with an elevated risk of SSPE.

In the present case, typical SSPE symptoms including insidious onset of mental deterioration and personality changes followed by motor dysfunction, myoclonic jerks, and extreme neurologic dysfunction led to the clinical suspicion of SSPE. The diagnosis of SSPE was supported by immunological evidence of intrathecal antimeasles virus antibody response as well as ancillary findings such as histologic features, typical EEG with a periodic complex pattern, and diffuse brain atrophies on MRI. On brain biopsy, no intranuclear inclusions were observed, which is not unusual in the sclerotic phase of SSPE. ${ }^{2)}$ As SSPE is a rare disease that can be mistaken for other neurodegenerative diseases, the diagnosis of SSPE can be easily missed or delayed. ${ }^{1)}$ Neurometabolic diseases such as neuronal ceroid lipofuscinosis or mitochondrial disease and also autoimmune encephalitis may present in a similar fashion. Thus, CSF measles antibody testing should be considered even in immunized patients with subacute altered mentality and myoclonic seizures before the administration of immunosuppressive therapies.

Although no curative therapy is currently available for SSPE, trials of treatment with INF- $\alpha$, INF- $\beta$, ribavirin, and oral inosiplex using different methodologies have reported beneficial results. Two large multicenter studies investigated the efficacy of oral inosiplex as a treatment for SSPE and suggested that it may increase survival. ${ }^{9)}$ Thereafter, combined oral inosiplex and intraventricular INF- $\alpha$ therapies were studied in 1990s and were found to significantly increase the remission rate. ${ }^{4)}$ Among 18 patients who received at least 12 months of oral inosiplex and intraventricular INF- $\alpha$ combination therapy, clinically stable status or improvement was seen in $44 \%$, with a spontaneous remission rate of $5 \% .{ }^{10)}$ Moreover, in 
Table 1. Clinical characteristics of reported therapy regimens in patients with SSPE

\begin{tabular}{|c|c|c|c|c|c|c|}
\hline Study & Country & Study design & $\begin{array}{l}\text { No. of patients/ } \\
\text { stage of patients }\end{array}$ & Regimen dose and type & Follow-up & Outcome \\
\hline Tomoda et al. ${ }^{14)}$ (2001) & Japan & Case series & $\begin{array}{l}\text { Stage II: } 1 \\
\text { Stage III: } 1\end{array}$ & $\begin{array}{l}\text { IV ribavirin } 70 \mathrm{mg} / \mathrm{kg} / \text { day every other } \\
\text { week plus } 3 \times 10^{6} \mathrm{IU} \text { of intrathecal IFN- } \alpha \\
\text { once a week for more than } 3 \text { months }\end{array}$ & 13 Months & $\begin{array}{l}\text { Stage II: improvement } \\
\text { Stage III: no improvement }\end{array}$ \\
\hline Hosoya et al. ${ }^{15)}(2001)$ & Japan & Case series & Stage II: 2 & $\begin{array}{l}\text { IV ribavirin } 30 \mathrm{mg} / \mathrm{kg} / \text { day for } 7 \text { days } \\
\text { at } 7 \text { day intervals plus } 3 \times 10^{6} \mathrm{IU} \text { of } \\
\text { intrathecal IFN- } \alpha 3 \text { times a week for } \\
\text { more than } 6 \text { months }\end{array}$ & 6 Months & Improvement \\
\hline Aydin et al..$^{11)}(2003)$ & Turkey & $\begin{array}{l}\text { Retrospective compara- } \\
\text { tive cohort study }\end{array}$ & $\begin{array}{l}\text { Protocol: } 19 \\
\text { Control: } 13 \\
\text { Stage }\end{array}$ & $\begin{array}{l}\text { Oral inosiplex (100 mg/kg/day) plus } \\
\text { subcutaneous IFN- } \alpha\left(10 \mathrm{mU} / \mathrm{m}^{2} / 3 \text { times }\right. \\
\text { a week) plus oral lamivudine }(10 \mathrm{mg} / \\
\mathrm{kg} / \text { day) for } 6 \text { months }\end{array}$ & 7-25 Months & $\begin{array}{l}\text { Stabilization/improvement } \\
\text { Protocol: } 7 / 19(36.8 \%) \\
\text { Control: 0/13 (0.0\%) }\end{array}$ \\
\hline Gascon $^{7)}(2003)$ & Japan & $\begin{array}{l}\text { Prospective randomized } \\
\text { trials }\end{array}$ & $\begin{array}{l}\text { Group A } 39 \\
\text { Group B } 28 \\
\text { Stage I-II }\end{array}$ & $\begin{array}{l}\text { Group A: Oral inosiplex alone } \\
\text { Group B: combined treatment } \\
\text { Both for } 6 \text { months }\end{array}$ & 3 Years & $\begin{array}{l}\text { Stabilization/improvement } \\
\text { Group A: } 13 / 39(34 \%) \\
\text { Group B; } 8 / 28(35 \%)\end{array}$ \\
\hline Anlar et al. ${ }^{13)}(2004)$ & Turkey & $\begin{array}{l}\text { Retrospective compara- } \\
\text { tive cohort study }\end{array}$ & $\begin{array}{l}\text { Group A: } 38 \\
\text { Group B: } 19 \\
\text { Stage I-III }\end{array}$ & $\begin{array}{l}\text { Intramuscular IFN- } \beta 60 \text { IU once a week: } \\
38 \text { patients } \\
\text { Subcutaneous IFN- } \beta 22 \text { IU } 3 \text { times a } \\
\text { week: } 19 \text { patients } \\
\text { Also, oral inosiplex } 50 \text { to } 100 \mathrm{mg} / \mathrm{kg} \text { daily }\end{array}$ & 1 Year & $\begin{array}{l}\text { Stabilization/improvement } \\
\text { Group 1: } 4 / 38(10.5 \%) \\
\text { Group 2: } 4 / 19(21 \%)\end{array}$ \\
\hline
\end{tabular}

SSPE, subacute sclerosing panencephalitis; IFN, interferon.

Table 2. Case studies of patients with SSPE that could survive long term

\begin{tabular}{lcccccccc}
\hline Study & Country & $\begin{array}{c}\text { Age at primary measles } \\
\text { infection (mo) }\end{array}$ & $\begin{array}{c}\text { Age at diagnosis of } \\
\text { SSPE (yr) }\end{array}$ & $\begin{array}{c}\text { Duration of } \\
\text { improvement (yr) }\end{array}$ & Treatment & F/U (yr) & Result \\
\hline${\text { Barraclough }{ }^{2)} \text { (1983) }}$ & UK & 15 & 15 & 5 & $\begin{array}{c}\text { Transfer factor (8 times for } \\
4 \text { months) }\end{array}$ & 9 Death \\
Miyazaki et al. ${ }^{5)}$ (2005) & Japan & Unknown & 8 & $7-8$ & $\begin{array}{c}\text { Intrathecal INF- } \alpha\left(1 \times 10^{6} \text { IU/ }\right. \\
\text { wk for 11 years) }\end{array}$ & 19 & Alive akinetic mutism \\
\hline
\end{tabular}

SSPE, subacute sclerosing panencephalitis; IFN, interferon.

a follow-up study of 67 patients, there were only 7 incidences of complications associated with this treatment, including 2 meningitis cases, one shunt infection, and four reservoir blocks. ${ }^{7)}$

Despite the lack of a clear advantage compared with oral inosiplex monotherapy, the combination approach is still recommended owing to theoretical synergistic effects. ${ }^{7)}$ Combination therapies with inosiplex and lamivudine with subcutaneous INF- $\alpha$ and high-dose intravenous ribavirin combined with intraventricular IFN- $\alpha$ were also associated with improvement. ${ }^{11)}$ However, further clinical results with ribavirin were questionable, and treatment with cimetidine, intravenous gamma globulin, and mesenchymal stem cell infusion showed no benefit. ${ }^{12)}$ Only 1 study reported that INF- $\beta$ administered subcutaneously combined with oral inosiplex may effectively treat SSPE. ${ }^{13)}$ CSF INF levels are low in patients with SSPE, and their peripheral mononuclear cells are thought to fail to produce INF in response to stimulation according to in vitro experiments. Exogenous INF- $\alpha$ therapy may potentiate natural killer cell activities and promote inhibition of measles virus replication. ${ }^{3)}$ In our patient, prolonged exogenous INF- $\alpha$ therapy did not downregulate CSF IgM and IgG antimeasles antibodies, but it did improve clinical symptoms. Thus, the role of CSF serology in the treatment of SSPE patients and the balance between viral replication prevention and altering the patient's immunology should be further investigated. Most earlier reports included only stage 1 and stage 2 patients with short followup periods, and long-term treatment effects in stage 3 SSPE patients remain unknown. The clinical characteristics of treatment regimens in patients with SSPE mentioned are summarized in Table 1.

Long-term stabilization or remission in SSPE is rare. ${ }^{1)}$ To our knowledge, our case represents one of the longest surviving patients with SSPE on long-term intraventricular INF- $\alpha$ therapy. The patient from the study of Barraclough CR (Table 2) was not treated with intrathecal administration. However, both of them could survive long-term 9 years or more. ${ }^{2)}$ The treatment duration differed among the survivors including the present case, and there was consistent progression of the disease after the initial symptom improvement.

Although no consistent recommendations have been established, long-term intraventricular IFN- $\alpha$ therapy may safely stabilize the neurological status in patients with advanced SSPE. Further studies are warranted to clarify the efficacy, dose, and duration as well as the efficacy of combination therapy with other antiviral or immunemodulating drugs. 


\section{Conflicts of interest}

No potential conflict of interest relevant to this article was reported.

\section{Acknowledgments}

We thank our patient and his family members for their participation in this study.

\section{References}

1. Prashanth LK, Taly AB, Ravi V, Sinha S, Rao S. Long term survival in subacute sclerosing panencephalitis: an enigma. Brain Dev 2006; 28:447-52.

2. Barraclough CR. Long-term survival of a case of subacute sclerosing panencephalitis. J Neurol Neurosurg Psychiatry 1983;46:457-8.

3. Risk WS, Haddad FS. The variable natural history of subacute sclerosing panencephalitis: a study of 118 cases from the Middle East. Arch Neurol 1979;36:610-4.

4. Anlar B, Yalaz K, Oktem F, Köse G. Long-term follow-up of patients with subacute sclerosing panencephalitis treated with intraventricular alpha-interferon. Neurology 1997;48:526-8.

5. Miyazaki M, Nishimura M, Toda Y, Saijo T, Mori K, Kuroda Y. Longterm follow-up of a patient with subacute sclerosing panencephalitis successfully treated with intrathecal interferon alpha. Brain Dev 2005; 27:301-3.

6. Jabbour JT, Garcia JH, Lemmi H, Ragland J, Duenas DA, Sever JL. Subacute sclerosing panencephalitis. A multidisciplinary study of eight cases. JAMA 1969;207:2248-54.

7. Gascon GG; International Consortium on Subacute Sclerosing Panencephalitis. Randomized treatment study of inosiplex versus combined inosiplex and intraventricular interferon-alpha in subacute sclerosing panencephalitis (SSPE): international multicenter study. J Child Neurol 2003;18:819-27.

8. Wendorf KA, Winter K, Zipprich J, Schechter R, Hacker JK, Preas C, et al. Subacute sclerosing panencephalitis: the devastating measles complication that might be more common than previously estimated. Clin Infect Dis 2017;65:226-32.

9. Fukuyama Y, Nihei K, Matsumoto S, Ebina T, Kamoshita S, Sato T, et al. Clinical effects of MND-19 (Inosiplex) on subacute sclerosing panencephalitis--a multi-institutional collaborative study--The Inosiplex-SSPE Research Committee. Brain Dev 1987;9:270-82.

10. Gascon G, Yamani S, Crowell J, Stigsby B, Nester M, Kanaan I, et al. Combined oral isoprinosine-intraventricular alpha-interferon therapy for subacute sclerosing panencephalitis. Brain Dev 1993;15:346-55.

11. Aydin OF, Senbil N, Kuyucu N, Gürer YK. Combined treatment with subcutaneous interferon-alpha, oral isoprinosine, and lamivudine for subacute sclerosing panencephalitis. J Child Neurol 2003;18:104-8.

12. Kuşkonmaz B, Uçkan D, Yalnizoğlu D, Günel M, Karli Oğuz K, Konuşkan B, et al. Mesenchymal stem cell application in children with subacute sclerosing panencephalitis. Dev Med Child Neurol 2015; 57:880-3.

13. Anlar B, Aydin OF, Guven A, Sonmez FM, Kose G, Herguner O. Retrospective evaluation of interferon-beta treatment in subacute sclerosing panencephalitis. Clin Ther 2004;26:1890-4.

14. Tomoda A, Shiraishi S, Hosoya M, Hamada A, Miike T. Combined treatment with interferon-alpha and ribavirin for subacute sclerosing panencephalitis. Pediatr Neurol 2001;24:54-9.

15. Hosoya M, Shigeta S, Mori S, Tomoda A, Shiraishi S, Miike T, et al. High-dose intravenous ribavirin therapy for subacute sclerosing panencephalitis. Antimicrob Agents Chemother 2001;45:943-5. 